\title{
Production processes and statistical analysis of ceramic liner-hole parameters for sustainability and improved thermal efficiency of clean biomass stoves
}

\author{
Kenneth Donkor ${ }^{1}$, George Yaw Obeng ${ }^{2,}$, Richard Opoku ${ }^{2}$, and Anthony Agyei-Agyemang ${ }^{2}$ \\ 1 Technology Consultancy Centre, College of Engineering, Kwame Nkrumah University of Science and Technology, Kumasi, \\ Ghana \\ 2 Department of Mechanical Engineering, College of Engineering, Kwame Nkrumah University of Science and Technology, \\ Kumasi, Ghana
}

Received: 14 March 2021 / Received in final form: 29 June 2021 / Accepted: 30 June 2021

\begin{abstract}
In engineering, ceramic liners are used as heat retention, insulation, and wear-resistant components for industrial and domestic applications. However, due to lack of production standards, particularly under small industrial operations, there is variation in liner-hole diameter and inter-hole spacing of liners used in clean biomass stoves. This study assessed the production processes and analysed ceramic liner-hole diameters and inter-hole spacings for standardisation. Standardising liner-hole parameters is a major process towards sustainability and improved efficiency. Methods employed were - material composition, particle size distribution analysis, study of production processes, and 51 liner-hole diameters and 66 inter-holes spacing were randomly sampled and analysed. The results indicated material composition of clay (70\%), sand (23\%), and sawdust $(7 \%)$ of various particle sizes. A flow chart diagram of 7 production processes was created for standardisation. At $95 \%$ C.I, liner-hole diameter of $\varnothing 20.8 \pm 2(0.66) \mathrm{mm}$ and inter-hole spacing of $27.5 \pm 2(1.06) \mathrm{mm}$ were determined. Mean liner-hole diameter of $\varnothing 21.03 \mathrm{~mm}$ resulted in a relatively high thermal efficiency, $\eta_{T}=37 \%$. For practical applications, liner-hole diameter of $\varnothing 21 \mathrm{~mm}$ and inter-hole spacing of $30 \mathrm{~mm}$ are recommended. Standardising the production processes and the liner-hole parameters will contribute to sustainable production and thermal efficiency improvement.
\end{abstract}

\section{Introduction}

The ceramic liner is utilised as heat retention, insulation, corrosion and wear resistant product for industrial and domestic applications [1,2]. Depending on the desired property and application, ceramic liners could be made from different material combination such as $\mathrm{Al}_{2} \mathrm{O}_{3}-\mathrm{Cr}_{2} \mathrm{O}_{3}-\mathrm{SiC}$, and $\mathrm{Al}_{2} \mathrm{O}_{3}-\mathrm{ZrO}_{2}-\mathrm{TiO}_{2}$ composites [3], silicon-based $\mathrm{SiBCNZr}$ composite [4], $\mathrm{Na}_{2} \mathrm{Al}_{2} \mathrm{Ti}_{6} \mathrm{O}_{16}$ composite [5] and silica sand tailings [6]. Industrial uses of ceramic materials include surface strengthening [7] and reducing heat transfer in high temperature applications such as in diesel ignition engines [8]. Ceramic liners are also used in marine diesel engines due to IMO Sulphur 2020 regulation, because new fuels have lower sulphur, more corrosion and wear.

\footnotetext{
* e-mail: gyobeng.coe@knust.edu.gh
}

For domestic applications, ceramic liners are heavily used for heat retention in cooking and burner devices [2]. Cooking is one of the major energy costs in the homes of many developing countries [9]. In these households, biomass still remains the dominant cooking fuel [10-12], and the numbers are estimated to rise especially in subSaharan Africa [13]. In Ghana for example, more than $75 \%$ of the population rely on biomass fuels for cooking [14]. Methods of reducing fuel cost for cooking including the use of improved biomass stoves [15] is therefore of high relevance.

For clean biomass stoves ceramic liner is one of the major components that help to reduce biomass fuel consumption by as high as $40 \%$ through heat retention and metal cladding insulation [16]. Ceramic liners in clean biomass stoves are expected to be standardized to ensure reduced emissions and improved thermal efficiency [17]. Thermal efficiency is a measure of the portion of heat produced by the fuel that makes it directly to the substance 
in the cooking pot with the rest lost to the environment [17]. To increase air flow and improve thermal efficiency when using ceramic liners, parameters such as the linerhole diameter and inter-hole spacing must be taken into account.

Furthermore, analysing the composition and particle size distribution of the materials used for the production of the ceramic liner will unleash opportunities for improving the production processes. However, there is a lack of indepth scientific studies on ceramic liners, particularly those that are used for insulating clean cooking stoves.

The purpose of this study is to assess the material composition and particle size distribution, production processes, and performance metrics with focus on the association between the ceramic liner-hole diameters and thermal efficiency of ceramic liners produced by a typical clean energy stove company. The objectives of the study are to: determine the major materials that are used in the composition of ceramic liners; assess the production processes being employed to produce the ceramic liners; determine the ceramic liner-hole sizes and arrangement that are required for standard production; and analyse how ceramic liner-hole sizes influence thermal performance of the ceramic liner.

The outcome of this study will contribute to knowledge required by industries and small businesses to repurpose the production processes and standardise the diameter of the ceramic liner-holes and their arrangement for improved thermal efficiency and sustainable production. The innovation is that the materials used for production, the ceramic-liner product and the biomass fuel are all sustainably produced to improve thermal efficiency and achieve clean energy. With improved thermal efficiency, a significant amount of the heat from the biomass fuel will be transferred directly into the cooking pot without losing most of that energy to the environment.

\section{Materials and methods}

\subsection{The study areas and methods}

The study employed mixed methods of observation and survey, laboratory testing and statistical analysis. The first part was a close observation, notes taking and survey of the workers of Man and Man Enterprise Ltd - an award winning clean cooking Biomass Stove and Ceramic Liner Production Company located in Darko, a suburb of Kumasi, Ghana. The enterprise is sited on a 2 acre land, which is located near Kumasi. The enterprise has 24 workers including a manager, a secretary, an administrator, an accountant and 20 production staff. The enterprise manufactures 200 clean biomass stoves daily. It is reported that the company's production capacity in the year 2013 was about 28,000 stoves [18]. The stoves are distributed in several regions of Ghana and some markets in West Africa. A total of 14 respondents were interviewed using structured questionnaires. The respondents included: 2 administrative staff (manager and administrator); and 12 production staff comprising 1 fireman; 6 moulding persons; 4 metal fabricators; and 1 sprayer. The second part was the laboratory analysis of the materials composition and particle size distribution of the ceramic liner. The third part was the laboratory testing of random samples of ceramic liners fixed in clean cooking stoves.

\subsection{Material composition and particle size}

Clay, sawdust and sand were primarily the materials used for the production of the ceramic liners. These materials were sourced from different locations around the city of Kumasi, Ghana. The particle size distribution test was carried out in the Soil Mechanics Laboratory of the Department of Civil Engineering, Kwame Nkrumah University of Science and Technology, Kumasi, Ghana. To characterise the soil samples two main tests were performed, namely sieve analysis and hydrometer test using SDMT 422 to standardise the test method for particle size analysis of the soil samples. The results obtained in regard to the amount of each particle size (clay, sawdust, and sand) that was determined by the laboratory are presented in Table 2.

\subsection{Laboratory considerations, materials and conditions for testing the ceramic liners}

Three randomly selected ceramic lined stoves were tested at the Cookstove Testing and Expertise Laboratory (C-Lab) of KNUST in Kumasi, Ghana. The combustion chambers of the stoves were fitted with fired ceramic liners of 17 holes whose sizes and arrangements varied from stove to stove. Each stove had a door to regulate the flow of primary air into the combustion chamber. ISO Water Boiling Test (WBT 4.2.1) protocol was used to test each stove in 3 replicates on 3 phases - cold start; hot start; and simmering $[19,20]$. Charcoal fuel was used for testing the ceramic lined stoves. The calorific value for the charcoal was determined using bomb calorimeter. The moisture content of the charcoal fuel was determined using Delmhorst J-2000 moisture meter. The lab testing focused on measuring the thermal efficiency. Fuel consumed for each of the three stages were analysed as a time-weighted average to determine the WBT key indicators $[19,21,22]$. Data were analysed using WBT 4.2.3 data calculation spreadsheet.

\subsection{Theoretical consideration}

Thermal efficiency is a measure of interest since heat retention devices including ceramic liners are expected to have high thermal efficiency and reduced heat loss with less effect on the environment. High thermal efficiency signifies a greater capability to transfer the heat produced into the needed device. A key design requirement desired by most people is to achieve highest heat flow to where it is needed as useful energy. However, this does not happen in reality since heat flows out in several ways through the ceramic liner-holes to the cooking device and surroundings as heat loss [21]. Important metric that is of significant interest to this study is thermal efficiency. Thermal efficiency is a measure of the portion of heat produced by the fuel that made it directly to the water in the pot with the rest of the 
energy lost to the surroundings [22]. The thermal efficiency of unenclosed three-stone stoves is about $15 \%$ [22]. This means that in an unenclosed three-stone fire, only $15 \%$ of energy produced gets to the cooking pot with $85 \%$ lost to the environment [23]. Again, the thermal efficiency of traditional coalpot stove used in Ghana is about $23 \%$ $[24,25]$ implying that nearly $77 \%$ of the total heat is lost to the surroundings. In the case of an insulated rocket stove with pot skirt, only $35 \%$ of the total heat produced gets to the pot and $65 \%$ is lost to the environment [26]. While this seems like a modest increase over the three stone stoves, and other unenclosed traditional stoves, there are still large losses to the environment [26]. Generally, the heat bearing capacity of the material defines the heat loss by walls of the stove. The less the thermal conductivity, the less would be the heat loss [27].

Thermal efficiency $(\%)$

$$
=\frac{4.186(\mathrm{~T} 1 \mathrm{sf}-\mathrm{T} 1 \mathrm{si})(\mathrm{P} 1 \mathrm{fs}-\mathrm{P} 1 \mathrm{si}+\mathrm{Wsr}) / 2+2260 \mathrm{Wsv}}{\text { fsd.LHV }}
$$

where $\mathrm{T} 1 \mathrm{sf}=$ Water temperature at end of test $\left({ }^{\circ} \mathrm{C}\right)$; $\mathrm{T} 1 \mathrm{si}=$ Starting water temperature $\left({ }^{\circ} \mathrm{C}\right) ; \mathrm{P} 1 \mathrm{sf}=$ Mass of pot with water after test (grams); P1si $=$ Starting mass of pot with water (grams); Wsr = Effective mass of water simmered (grams); Wsv $=$ Water vaporized $($ grams); $\mathrm{f}$ $\mathrm{sd}=$ Equivalent dry fuel consumed (grams); LHV = Net calorific value (dry wood) $(\mathrm{kJ} / \mathrm{kg})$.

\subsection{Description of the ceramic liner}

The ceramic liner has 17 perforated holes that allow the flow of air and ash to fall through and be gathered at the base of the stove. It is made out of clay material which is moulded into a V-shape and fired clay (fired at $700-900^{\circ} \mathrm{C}$ ) that gives heat retention properties to the cookstove. When fixed inside the stove, the ceramic liner insulates the fire and keeps it hot. Further, the insulation prevents the heat from being conducted into the body of the stove instead of the cooking pot. Figure 1 shows the engineering and pictorial drawings of the ceramic liner.

Lining clean cooking stoves safeguard the metal casing from direct heat. It is expected that good quality clay will exhibit the following properties: retain strength once fired at a temperature of $900{ }^{\circ} \mathrm{C}$; be able to maintain its porosity when temperature is raised to $1150{ }^{\circ} \mathrm{C}$; should not distort when fired at $1250^{\circ} \mathrm{C}$ [28]; and the thermal conductivity should not be more than $2.5 \mathrm{~W} /(\mathrm{mK})$ at $500^{\circ} \mathrm{C}$ [29]. Further, in order to minimize the possibility of cracking after firing, its reduction in size should be below $8 \%$ [13]. Any clay that possesses the above quality is a fireclay. Clay reduces in size when being dried or fired and it should be noted that various clay reduces in size at varying rates from $4 \%$ to $15 \%$ [30]. Clay shrinkage can be computed using equation (2) [28].

$\begin{aligned} \text { Clay shrinkage }= & \frac{\text { Dry measurement }- \text { Fired measurement }}{\text { Dry measurement }} \\ & \times 100 \%\end{aligned}$
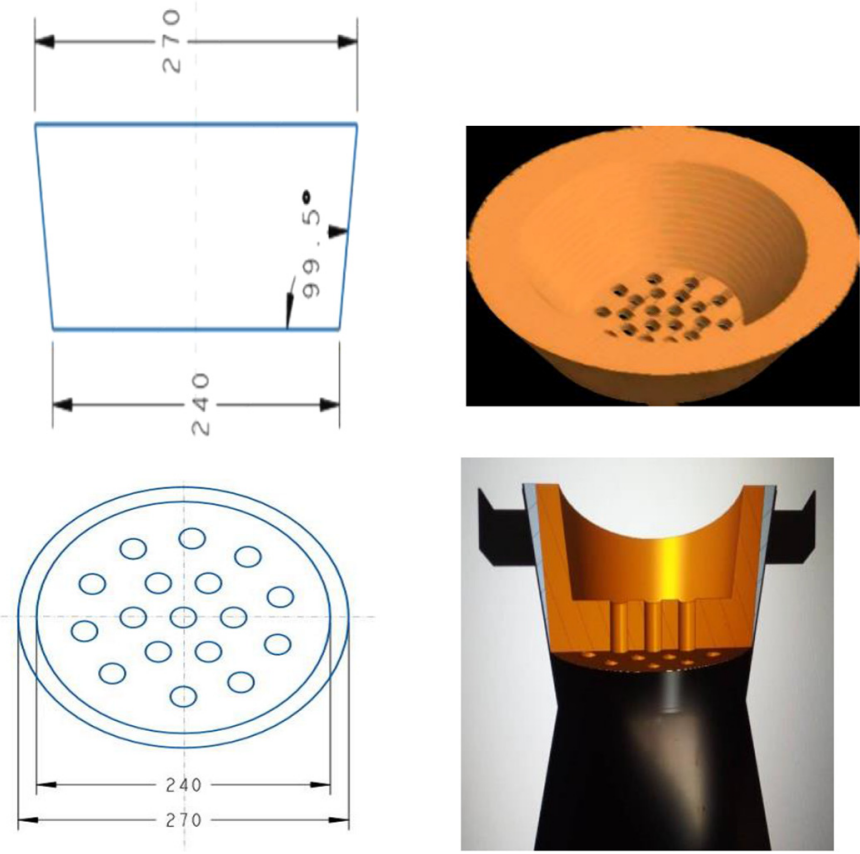

Fig. 1. Engineering drawing and pictorial view of a ceramic liner and clean biomass stove.

\subsection{Statistical methods and data analysis}

\subsubsection{Central limit theorem and coefficient of variation}

Let $x_{1}, x_{2}, \ldots, x_{n}$ be a random sample from a distribution with (finite) mean $\mu$ and (finite) variance $\sigma^{2}$. For large sample size of $n$, sample mean $x$ follows an approximate normal distribution. Now, the following equations of the mean and standard deviation are used [31,32]:

$$
\operatorname{Mean} \overline{\mathrm{x}}=\frac{\mathrm{X} 1+\mathrm{X} 2+\mathrm{X} 3, \ldots,+\mathrm{Xn}}{\mathrm{n}}=\frac{\sum_{\mathrm{i}=1}^{\mathrm{n}} \mathrm{X}}{\mathrm{n}}
$$

where $n=$ sample size.

$$
\text { Standard error of sample mean, } \sigma_{\overline{\mathrm{x}}}=\frac{\sigma}{\sqrt{ } \mathrm{n}}
$$

where $\sigma=$ standard deviation of the population mean.

The confidence intervals for the mean with large samples and standard deviation of the sample mean at $95 \%$ confidence interval will be estimated based on the empirical rule using equation (5):

$$
\text { Lower limit }=\overline{\mathrm{x}}-2 \sigma ; \text { Upper limit }=\overline{\mathrm{x}}+2 \sigma
$$

Coefficient of variation $(\mathrm{CV})$ is also known as relative dispersion [31]. It is useful when comparing two data sets that are not exactly alike, especially if the different data sets are not measured using the same units [31,32]. It measures the percentage of variation in data compared to the mean. CV is calculated using the formula stated in equation (6).

$$
\text { Coefficient variation } \mathrm{CV}=\left(\frac{\mathrm{s}}{\overline{\mathrm{x}}}\right) 100 \%
$$

where $S=$ sample standard deviation;

$\bar{x}=$ sample mean. 
Table 1. Material composition and purpose of using the materials.

\begin{tabular}{|c|c|c|c|c|}
\hline Material & $\begin{array}{l}\text { Ratio per } \\
\text { batch }\end{array}$ & $\begin{array}{l}\text { Weight of material } \\
\text { per wheel barrow }(\mathrm{kg})\end{array}$ & $\begin{array}{l}\% \text { of total weight } \\
\text { of materials }\end{array}$ & Purpose of using the materials \\
\hline Clay & 3 & $106.6 \times 3=319.8$ & $70 \%$ & $\begin{array}{l}\text { Clay is chosen due to its relatively low thermal } \\
\text { conductivity } \leq 2.5 \mathrm{~W} /(\mathrm{m} . \mathrm{K}) \text { at } 500{ }^{\circ} \mathrm{C} \text { and reddish } \\
\text { colour after firing. }\end{array}$ \\
\hline Sand & 1 & $106.8 \times 1=106.8$ & $23 \%$ & $\begin{array}{l}\text { Sand adds roughness and strength to the wet clay } \\
\text { and prevents cracking }\end{array}$ \\
\hline Sawdust & 1 & $31.3 \times 1=31.3$ & $7 \%$ & $\begin{array}{l}\text { The ceramic liner becomes porous when sawdust } \\
\text { is included. }\end{array}$ \\
\hline \multicolumn{2}{|c|}{ Total weight } & $458 \mathrm{Kg}$ & $100 \%$ & \\
\hline
\end{tabular}

\subsubsection{The empirical rule}

Assuming the data being used are normally distributed, then the empirical rule can be used and it is expressed as follows:

i. $\mathrm{M} \pm 1 \mathrm{~S}$ indicating $68 \%$ of observations in the range $(\mathrm{M} \pm 1 \mathrm{~S})$.

ii. $\mathrm{M} \pm 2 \mathrm{~S}$ indicating $95.4 \%$ of observations in the range $(\mathrm{M} \pm 2 \mathrm{~S})$.

iii. $\mathrm{M} \pm 3 \mathrm{~S}$ indicating $99.7 \%$ of observations in the range $(\mathrm{M} \pm 3 \mathrm{~S})$.

\subsubsection{Data analysis}

Two key variables were focused on, namely the ceramic liner-hole diameter and inter-tooth spacings. Methods and tools for statistical analysis included: frequency distribution; central tendency; dispersion and measures of variation; empirical rule for normal distribution; and confidence intervals. To provide a graphical representation of the data and analytical guide for corrective action, frequency distribution, frequency curve, central tendency, 68-9599.7 rule and confidence interval were employed for data analysis. Normal distribution template in Microsoft Excel 2010 (originally by W.F. Coleman, 1997 and adapted by [33] was used to plot the various normal distributions for this paper. Level of significance $p<0.05$ is used in this analysis.

\section{Results and discussion}

\subsection{Material composition}

The results in Table 1 indicate the ratio per batch of the major materials including: 3-parts of clay to 1-part of sand to 1-part of sawdust with percentage of the total weight of materials being clay $(70 \%)$, sand $(23 \%)$ and sawdust $(7 \%)$. The weight of material per wheel barrow of $458 \mathrm{~kg}$ per batch could produce 92 ceramic liners. If on average 6 batches are produced in a day; then a daily production of about 552 ceramic liners is realized. In addition to the composition of the materials, the purpose for which the materials are used is also presented. The varied nature of clay and additive materials such as sawdust makes the study of the physical properties of clay including its strength an intricate one [34-36]. What is most significant is that moulded and clay fired liners have the strength, durability and can give heat retention properties to the stove.

\subsubsection{Particle size distribution}

Table 2 presents data on the grading test results of unsieved clay, unsieved sand and unsieved sawdust materials. From the results, about $99.7 \%$ of the clay had particle size of up to $2.00 \mathrm{~mm}$. Nearly $97 \%$ of the sand had particle size up to $3.35 \mathrm{~mm}$, while in the case of sawdust about $78.0 \%$ of the particle size was up to $0.60 \mathrm{~mm}$. Some amount of sand, silt and gravels were found in both the unsieved clay and unsieved sand. However, sand and silt accounted for about $70-80 \%$ of the ceramic liner materials. The relatively high content of sand and silt in the composition might explain why nearly $10-20 \%$ of the ceramic liners get broken during firing.

\subsection{Production processes}

Figure 2 is the flow chart that indicates seven production processes required for producing the ceramic liners. The production processes determined are as follows: (1) Composition and preparation of the liner; (2) Moulding the ceramic liner; (3) Making holes in the ceramic liner; (4) Drying the ceramic liner; (5) Firing the ceramic liner; (6) Making casing for the liner; and (7) Fixing the ceramic liner in a metal casing.

Step 1: Composition and preparation of the liner

From the study, sustainable materials that were used for the production of the ceramic liners included clay, sand and sawdust in the proportion of 3:1:1 by volume. In spite of the fact that the $3: 1: 1$ proportion is what was followed, in some cases when the clay was felt to contain more sand, the composition was adjusted by reducing the amount of sand. Another observation was that those working on the composition did not entirely adhere to the $3: 1: 1$ proportion owing to speed of production, and lack of quality control measures. In planning the composition the clay was doused in water in a pit for one day. The next day sand and sawdust were included and thereafter blended together using an electric pug process. 
Table 2. Summary of particle size distribution for composing the ceramic liner (one batch).

\begin{tabular}{|c|c|c|c|c|c|}
\hline Grading test of materials & $\begin{array}{l}\text { Sieve } \\
\text { size }(\mathrm{mm})\end{array}$ & $\begin{array}{l}\text { Weight } \\
\text { retained }(\mathrm{kg})\end{array}$ & $\begin{array}{l}\text { Percentage } \\
\text { retained (\%) }\end{array}$ & $\begin{array}{l}\text { Percentage } \\
\text { passed (\%) }\end{array}$ & $\begin{array}{l}\text { Percent of gravel, silt } \\
\text { sand and clay in } \\
\text { unsieved materials }\end{array}$ \\
\hline \multirow{4}{*}{ Unsieved Clay (70.9g) } & 4.75 & 0.15 & 0.21 & 99.79 & Gravel (1\%) \\
\hline & 3.35 & 0.10 & 0.14 & 99.65 & Sand $(29 \%)$ \\
\hline & 2.00 & 0.38 & 0.51 & 99.65 & Silt $(43 \%)$ \\
\hline & 0.075 & 7.04 & 9.93 & 77.89 & Clay $(27 \%)$ \\
\hline \multirow{4}{*}{ Unsieved Sand (95.6 g) } & 4.75 & 0.82 & 0.88 & 99.14 & Gravel (16\%) \\
\hline & 3.35 & 1.79 & 1.87 & 97.14 & Sand $(65 \%)$ \\
\hline & 2.00 & 12.89 & 13.49 & 83.77 & Silt $(15 \%)$ \\
\hline & 1.00 & 21.70 & 22.71 & 61.08 & Clay $(4 \%)$ \\
\hline \multirow{4}{*}{ Sawdust (60.0g) } & 0.600 & 13.19 & 21.96 & 78.02 & \\
\hline & 0.425 & 14.67 & 24.45 & 53.57 & \\
\hline & 0.300 & 16.28 & 27.13 & 26.43 & \\
\hline & 0.100 & 12.16 & 20.27 & 6.17 & \\
\hline
\end{tabular}

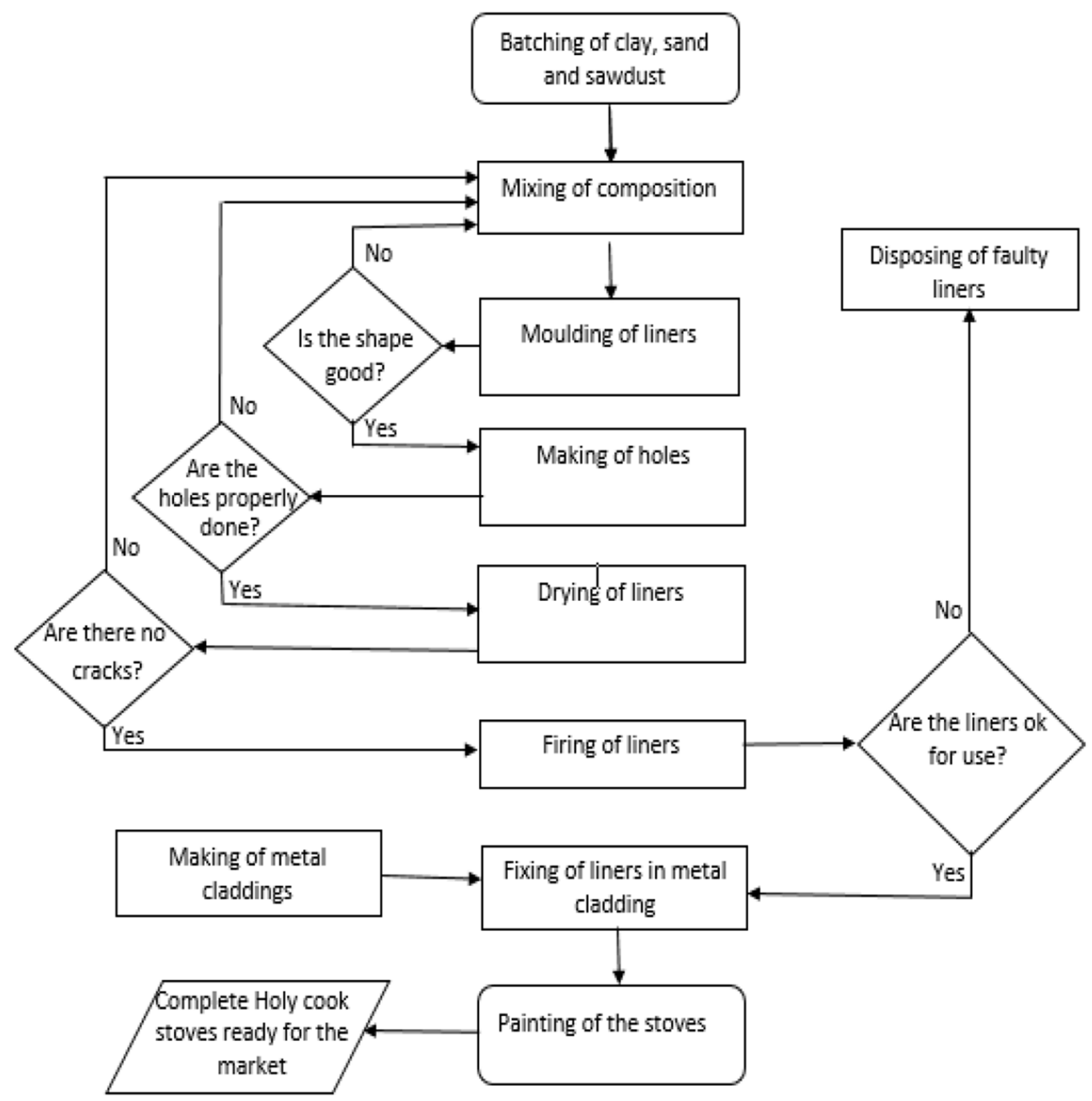

Fig. 2. Flow chart indicating the production processes of the ceramic liner. Source: Authors own construct (2020). 
Table 3. Central tendency, dispersion and measure of variations.

\begin{tabular}{llcc}
\hline & Description & Ceramic liner hole diameter & Ceramic liner inter-hole spacing \\
\hline 1 & Number of observations (n) & 51 & 66 \\
2 & Minimum value & 18.4 & 15 \\
3 & Maximum value & 22.4 & 39 \\
4 & Median & 20.8 & 29 \\
5 & Mean & 20.8 & 27.5 \\
6 & Mode & 21.1 & 27 \\
7 & Standard deviation (SD) & 0.66 & 1.06 \\
8 & Coefficient of variation (CV) & $3.17 \%$ & $3.85 \%$ \\
9 & Standard error (SE) & 0.09 & 0.13 \\
\hline
\end{tabular}

\section{Step 2: Moulding the liner}

Before the liners were formed, the blend was pressed continuously with the hand to free any air bubbles and a few undesirable materials. The Jigger-Jolley machine was utilized for the mass production of the liners; additionally for consistency in the size of the liners. Wood cinder was sprinkled to the side metal form of the Jigger-Jolley machine in order to remove it simply. There were 3 workshop inlets for forming the liners; these were worked by 3 persons. When the shape of the liner was mutilated, it was sent back to the clay pit to be sustainably re-produced through recycling and reusing to reduce waste.

\section{Step 3: Making holes in the liner}

After the new liners have been formed, they are cleared out to dry for 24 hours. 17 perforations are physically made employing a cylindrical metal device with a sharp edge. This number of perforations differs from those of the Sazawa charcoal stove which has between 19 and 44 holes [37]. Additionally, the number of liner-holes is different from the Kenyan Ceramic Jiko, whose liner-holes vary from small stoves of 14 liner-holes big stoves of 19 liner-holes [38]. It was noted that no specific design was utilized in making the liner-holes and thus the hole sizes and interhole spacing are distinct from stove to stove.

\section{Step 4: Drying the liners}

Typically, one day after making the liner-holes, they are gently stacked on each other to dry on wooden racks within the open of a shed for 7 days. They were at times opened to the sun. It took about 10 to 14 days to dry the ceramic liners, particularly during the wet season. A ceramic liner is deemed to be sufficiently dried when the colour changed from dim brown to light creamy brown.

\section{Step 5: Firing the liners}

After cross-checking that the liners are dried enough, they are again stacked on each other face down within the furnace. The furnace employs firewood and can fire almost 1500 ceramic liners. When the furnace is completely filled up with the liners, the entrance is covered. 3 spy-holes are made to inspect the liners. It takes approximately 3 days to fire the liners. During the first day the furnace is heated slowly, thereafter it runs full blast for two days. When the spy holes are peeped and the interior of the furnace is seen to be gleaming or the colour is a bit ruddy, the required temperature is likely to be reached. After the liners are fired, the furnace cools down for 24 hours before the liners get removed from the furnace. To find out whether the liner is sufficiently fired, it is tapped with a knuckle and the sound would indicate the readiness of the liners. From experience about $10-20 \%$ of the liners might have surface cracks and defects.

\section{Step 6: Making the metal casing}

Scrap sheet metals of thickness $0.4-0.5 \mathrm{~mm}$ are used for the fabrication of the metal casing. In order to have standard parts, templates are utilized to guide the marking and cutting of the various parts for the metal casing. The template is set on a sheet metal and the outline is drawn with a pencil or a nail, the marked out parts are cut out of the sheet metal. The cut out parts are joined together using fabrication methods like folding and riveting. Owing to the lack of adherence to standards, the metal casing fabricators do not utilize the same measurement and templates; hence there is a lack of interchangeability and standardization of the entire fabrication of the metal casing.

\section{Step 7: Fixing the liner in metal casing}

After the liners have been physically inspected those that do not show any cracks are selected to be fixed in the metal casing. Since the liner cannot sit freely within the metal casing, it is bonded to the casing. A mortar blend of 2-parts cement to 1-part sand is smeared on the back side of the liner. In the case of the Kenyan Ceramic Jiko the mortar blend for holding the liner to the metal casing is a blend of vermiculite and cement or nearby materials like mica, fiery remains or lime [39]. At this point, the liner is carefully set within the upper portion of the metal casing. Spill over mortar is wiped off and cleaned by employing a damp cloth and the bonded liner takes some time to set.

\subsection{Statistical analysis of liner-hole parameters}

The study assessed 51 liner-holes and 66 inter-hole spacing. The results in Table 3 indicate liner-hole diameter ranged from $\min =18.4$ to $\max =22.4 \mathrm{~mm}$ and inter-hole spacings ranged from $\min =15 \mathrm{~mm}$ to $\max =39 \mathrm{~mm}$. The wide range of liner-hole sizes and inter-hole spacings could be as a result of quick random perforations of the ceramic liners without the use of a standard guiding tool or template. Clean cooking biomass stove producers insulate their stoves with ceramic liners to protect the stove and minimize heat loss. This produces a hotter flame leading to a better efficiency and improved performance [25]. 

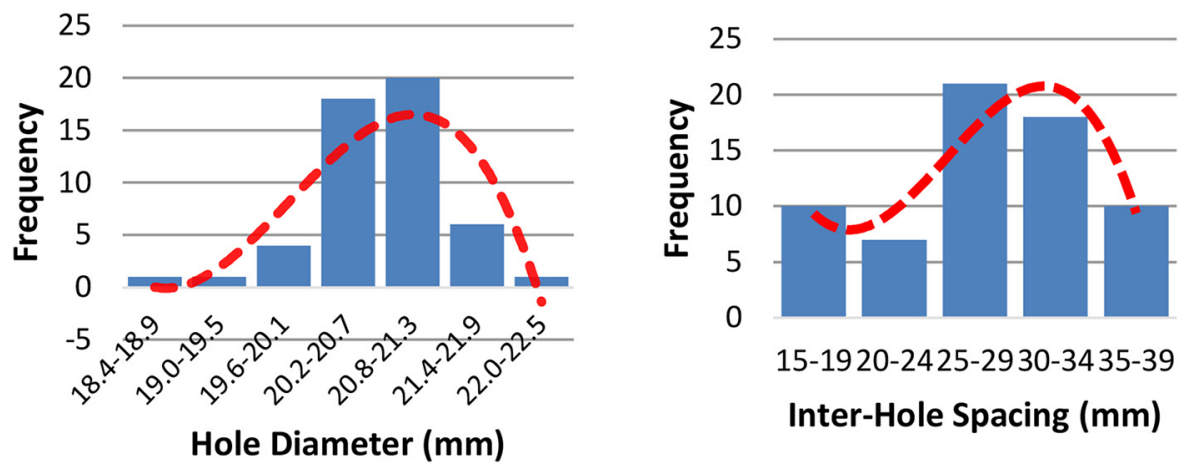

Fig. 3. Frequency curves of ceramic liner-hole diameter and inter-hole spacing.
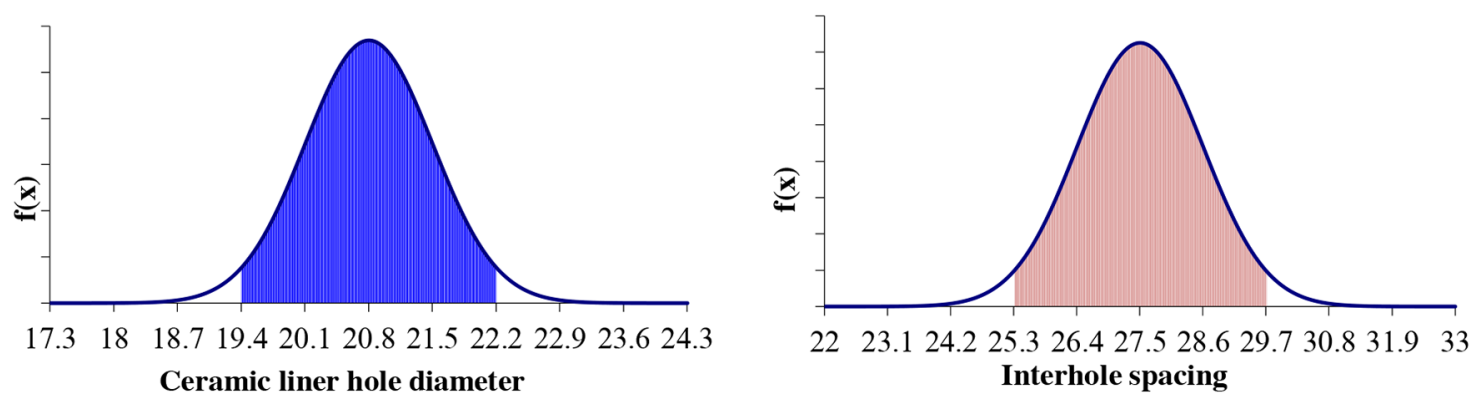

Fig. 4. Normal distribution showing $95.45 \%$ of observations in the range $(M \pm 2 \mathrm{~s})$.

The ceramic liner insulates the metal casing from being consumed by fire [34]. The size and arrangement of the perforated holes in ceramic liners help improve air circulation and good combustion.

\subsubsection{Frequency distribution}

The two frequency distributions of the liner-hole diameters and inter-hole spacings shown in Figure 3 indicate where most of the data are concentrated, namely around linerhole diameters of $\varnothing 20.2$ to $\varnothing 21.3 \mathrm{~mm}$ and inter-hole spacings of $25 \mathrm{~mm}$ to $34 \mathrm{~mm}$. Analysis of the two frequency distributions will help make decisions on the optimum liner-hole size and inter-hole spacing of the ceramic liners.

\subsubsection{Central tendency, dispersion and measures of variation}

To understand the central tendency of the data, mean $(M)$, median $\left(M_{d}\right)$ and mode $\left(M_{o}\right)$ can be very useful for statistical quality control analysis. Table 3 presents the following central tendency values of the ceramic liner: linerhole diameter $\left(M=\varnothing 20.8 \mathrm{~mm} ; \quad M_{d}=\varnothing 20.8 \mathrm{~mm} ; M_{o}=\right.$ $\varnothing 21.1 \mathrm{~mm} ; n=51)$; and inter-hole spacing $(M=27.5 \mathrm{~mm}$; $\left.M_{d}=29 \mathrm{~mm} ; M_{o}=27 \mathrm{~mm} ; n=66\right)$. The data presented in Table 3 indicates wider spread or deviation in the data for the inter-hole spacing with standard deviation $(\mathrm{SD}=1.06 \mathrm{~mm})$ when compared to the spread in the data for the liner-hole diameters $(\mathrm{SD}=0.66 \mathrm{~mm})$. To understand the variation in the data relative to the mean, coefficient of variation (CV) was used. CV measures the percentage of variation in the data relative to the sample mean - lower CV values are relatively more uniform [16] and more consistent than higher
CV values [32]. In Table 3, the computed CV value for the liner-hole diameter was $(\mathrm{CV}=3.17 \%)$, while that for the inter-hole spacings was $(\mathrm{CV}=3.85 \%)$. Although the two data sets showed some variation in data, since the CV for the liner-hole diameters was lower than the CV for the inter-hole spacings, it is implied that the data on the ceramic liner-hole sizes are more consistent than the data on the inter-hole spacings.

\subsubsection{Ceramic liner-hole sizes and arrangement required}

\section{The empirical rule and confidence interval}

Figure 4 presents the normal distribution curves and percent of the population in a given range for both the ceramic liner-holes and inter-hole spacings using their means and standard deviations. If it is assumed that the data are normally distributed, then the following empirical rule (or 68-95-99.7 rule) applies [31,40]. To enable the production process to work and be standardised within the 95\% confidence interval, it is expected that about $95 \%$ of all the liner-hole diameters and inter-hole spacings will fall within mean \pm 2 standard deviations. From the results, for $95 \%$ of the values around the mean, liner-hole diameter of $20.8 \pm 2(0.66) \mathrm{mm}$ and inter-hole spacings of $27.5 \pm$ $2(1.06) \mathrm{mm}$ were determined. The same approach was used in determining the inter-hole spacing between adjacent holes on concentric circles as shown in Figure 5. This implies that the study can confidently state that $95 \%$ of the entire data of the liner-holes and the inter-hole spacings fall within the stated range. These values could be used to standardise the size and arrangement of the liner-holes that would have implications for improved thermal efficiency. 


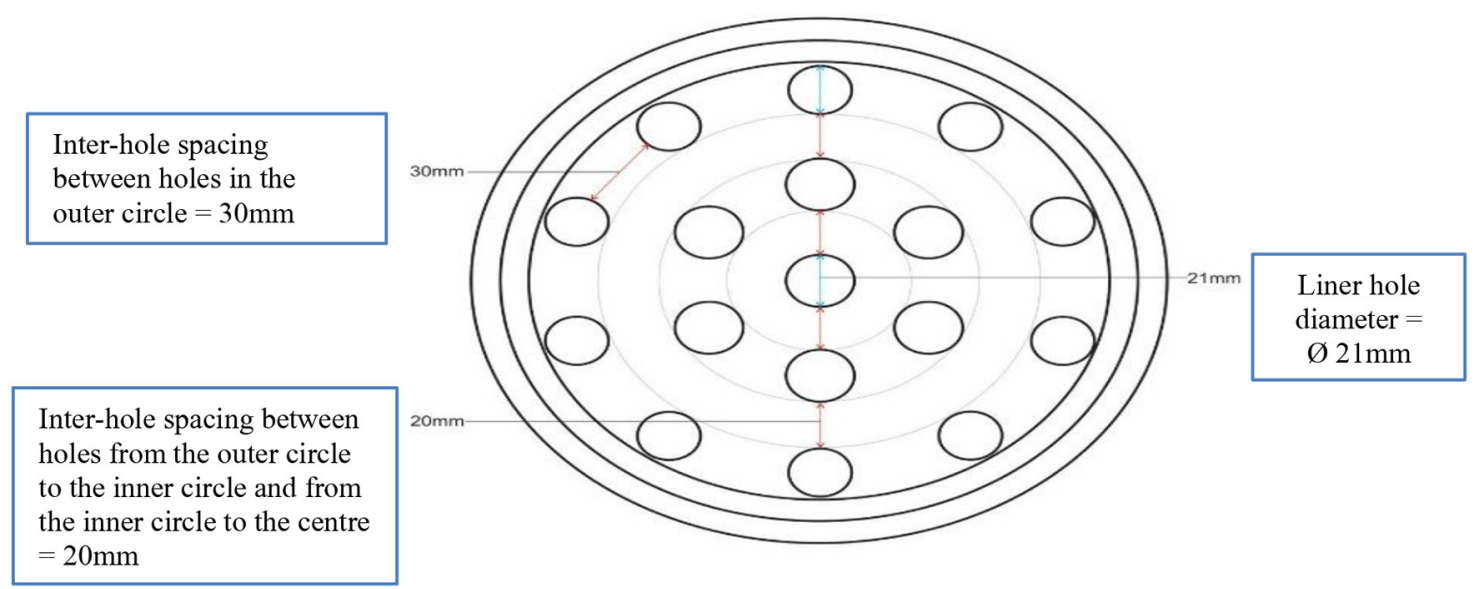

Fig. 5. Template for ceramic liner-hole diameter and inter-hole spacing.

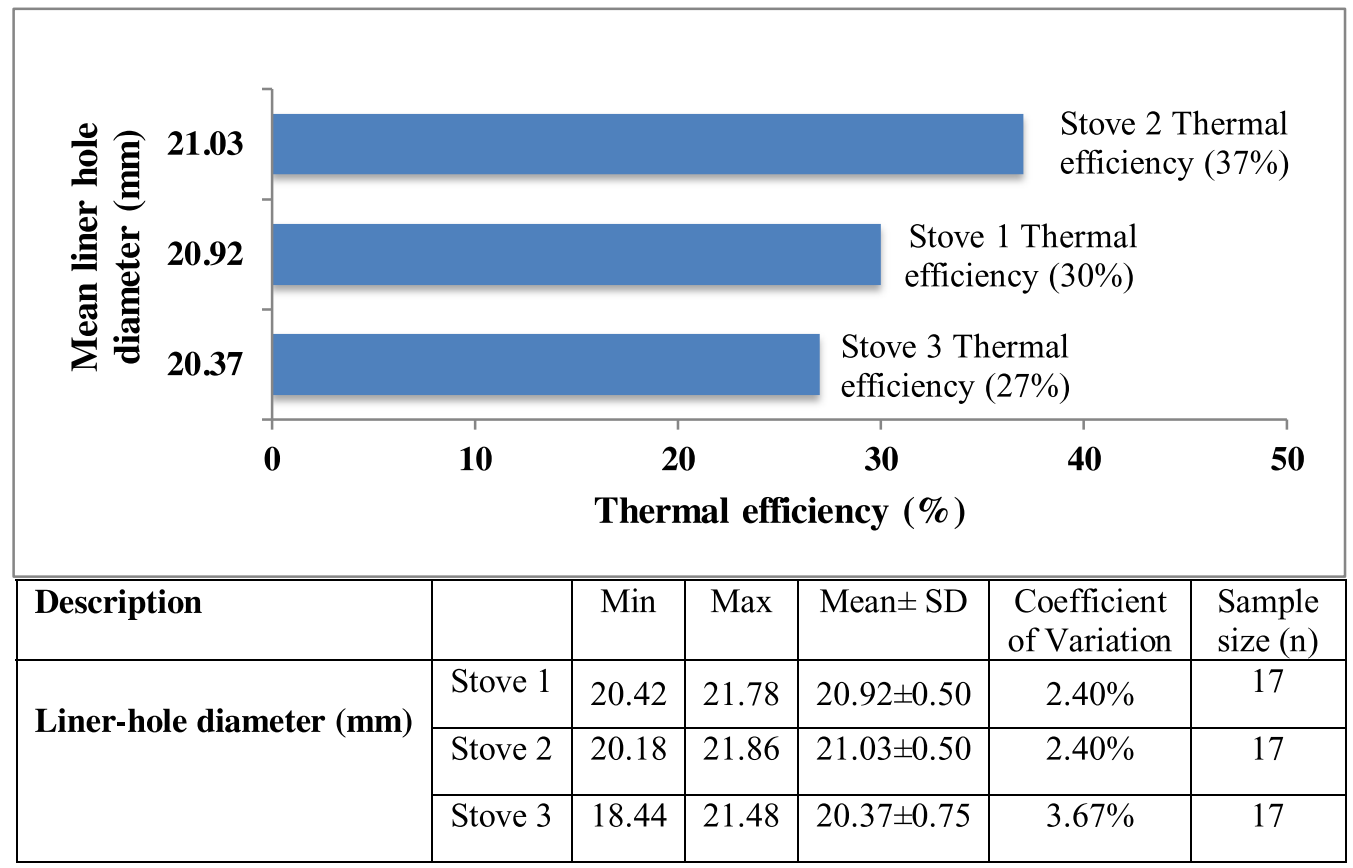

Fig. 6. Liner-hole diameter and thermal efficiency.

Practical implications for sustainable production

For practical purposes, the following dimensions shown in Figure 5 can be used to develop a template for standard production:

- Liner hole diameter should be $21 \mathrm{~mm}$.

- Inter-hole spacing between holes in the outer circle should be $30 \mathrm{~mm}$.

- Inter-hole spacing between adjacent holes on a concentric circle should be $20 \mathrm{~mm}$.

\subsection{Ceramic Liner-hole diameter and thermal efficiency}

Figure 6 shows horizontal bar plots of the ceramic linerhole diameter against thermal efficiency $\left(\eta_{T}\right)$. The bar plots indicate that among the three stoves with different liner hole diameters, stove 2 whose liner diameter was Ø20.18$\varnothing 21.86 \mathrm{~mm}$ gave the highest thermal efficiency of $\left(\eta_{T}=37 \%\right)$, followed by stove 1 with liner diameter of $20.42-21.78 \mathrm{~mm}$ and thermal efficiency of $\left(\eta_{T}=30 \%\right)$ and stove 3 with liner diameter of $18.44-21.48 \mathrm{~mm}$ and thermal efficiency of $27 \%$. From the statistical analysis, the ceramic liner-hole diameter that appears to give relatively high thermal efficiency has a mean size of $\varnothing 21 \mathrm{~mm}$. The lower coefficient of variation values of Stove $2(\mathrm{CV}=2.40 \%)$ and Stove $1(\mathrm{CV}=2.40 \%)$ suggest that there is relatively low variation in the size of the liner-holes of stoves $2\left(\eta_{T}=37 \%\right)$ and Stove $1\left(\eta_{T}=30 \%\right)$.

It is essential to optimize some design features such as the shape of the stove, distance between pot and burning charcoal, and size of the ceramic liner-holes [41]. Optimizing such features is likely to lead to enhanced air circulation to transfer heat and generate the required draft for efficient burning [41]. It is reported in the literature that improved stoves in Ghana such as Gyapa and Ahibenso have average thermal efficiencies ranging from $27.3 \%$ to $28.3 \%$ [42], and this is consistent with the value obtained for stove 3 
$\left(\eta_{T}=27 \%\right)$ whereas the value for stove $1\left(\eta_{T}=30 \%\right)$ is also consistent with thermal efficiencies of up to $36 \%$ for charcoal cookstoves [42]. Stove 2 recorded a thermal efficiency of $\left(\eta_{T}=37 \%\right)$. This is slightly above the reported values for similar stoves $[42,43]$. Thermal efficiency of a stove is good when a significant amount of the heat from the fuel is transferred directly into the pot without losing most of that energy [22].

\section{Conclusions}

The study assessed the material composition, production processes and liner-hole parameters of the ceramic liner. To characterise the materials used for production, particle size distribution test was carried out in the laboratory. Furthermore, various liner-hole diameters and inter-hole spacings were randomly sampled, measured and statistically analysed. The study established that clay, sand and sawdust with distinct purposes and proportions are the primary materials used for production of the ceramic liners. Flow chart diagram of seven production processes was created out of the study. From the statistical analysis, the ceramic liner that resulted in relatively high thermal efficiency had a mean liner-hole diameter of Ø21.03 $\mathrm{mm}$. For practical and wider applications, the following dimensions have to be repurposed for standard production and improved thermal performance - liner-hole diameter should be Ø21 mm; inter-hole spacing between liner-holes in the outer circle should be $30 \mathrm{~mm}$; and inter-hole spacing between liner-holes on concentric circles should be $20 \mathrm{~mm}$. Adequate air circulation within the liner combustion chamber helps burn the fuel completely. These results are significant contribution to knowledge required to standardise ceramic liner-hole size and arrangement for sustainable production and improved thermal efficiency.

Special thanks go to the staff of Man and Man Enterprise (an award winning clean cooking stove company in Ghana) as well as the technicians working in the Laboratories where the equipment for testing were used.

\section{References}

1. N. Takahashi, S. Hashimoto, Y. Daiko, S. Honda, Y. Iwamoto, High-temperature shrinkage suppression in refractory ceramic fiber board using novel surface coating agent, Ceram. Int. 44, 16725-16731 (2018)

2. S. Chalia, M.K. Bharti, P. Thakur, A. Thakur, S.N. Sridhara, An overview of ceramic materials and their composites in porous media burner applications, Ceram. Int. 47, 1042610441 (2021)

3. S. Chinnusamy, V. Ramasamy, S. Venkatajalapathy, G.V. Kaliyannan, S.K. Palaniappan, Experimental investigation on the effect of ceramic coating on the wear resistance of Al6061 substrate, J. Mater. Res. Technol. 8, 6125-6133 (2019)

4. Q. Zhu et al., Ablation properties and mechanisms of BNcoated Cf-reinforced SiBCNZr ceramic composites under an oxyacetylene combustion torch, Ceram. Int. 47, 15533-15541 (2021)
5. P. Gehre, M.M. Mata, C.G. Aneziris, Synthesis and properties of Na2Al2Ti6O16-containing ceramic materials, J. Alloys Compd. 776, 116-122 (2019)

6. J. Zhang, T. Liu, Q. Huang, Z. Luo, A. Lu, L. Zhu, Preparation, properties characterization and structure formation mechanism of silica sand tailings-based ceramic materials, Mater. Chem. Phys. 255, 123611 (2020)

7. L. Hu, Y. Wang, Silicon carbonitride ceramic surfacemodified nanoporous aluminum alloy by preceramic polysilazane precursor for surface strengthening, Mater. Sci. Eng. B 267, 115113 (2021)

8. S.M. Abbas, A. Elayaperumal, G. Suresh, A study on combustion and performance characteristics of ceramic coated (PSZ/Al2 O3) and uncoated piston - D.I. engine, Mater. Today Proc. 45, 1328-1333 (2021)

9. T. Gross et al., Potential of biogas production to reduce firewood consumption in remote high-elevation Himalayan communities in Nepal, Renew. Energy Environ. Sustain. 8, 1-6 (2017)

10. Z. Gebreegziabher, A.D. Beyene, R. Bluffstone, P. Martinsson, A. Mekonnen, M.A. Toman, Fuel savings, cooking time and user satisfaction with improved biomass cookstoves: evidence from controlled cooking tests in Ethiopia, Resour. Energy Econ. 52, 173-185 (2018)

11. K. Bakhsh, A. Sadiqa, M.A. Yasin, S. Haider, R. Ali, Exploring the nexus between households' choice of cooking fuels, sanitation facilities and access to information in Pakistan, J. Clean. Prod. 257, 120621 (2020)

12. D.K. Kidmo, K. Deli, B. Bogno, Status of renewable energy in Cameroon, Renew. Energy Environ. Sustain. 2, 1-11 (2021)

13. R. Bar, J. Reinhard, A. Ehrensperger, B. Kiteme, T. Mkunda, W.S. Von Dach, The future of charcoal, firewood, and biogas in Kitui County and Kilimanjaro Region: Scenario development for policy support, Energy Policy 150, 112067 (2021)

14. E.D.S. Van Vliet et al., Current respiratory symptoms and risk factors in pregnant women cooking with biomass fuels in rural Ghana, Environ. Int. 124, 533-540 (2019)

15. R. Suresh, V.K. Singh, J.K. Malik, A. Datta, R.C. Pal, Evaluation of the performance of improved biomass cooking stoves with different solid biomass fuel types, Biomass Bioenergy 95, 27-34 (2016)

16. SEED, Man \& Man Enterprise (2020). Hosted by adelphi research gGmbH https://www.seed.uno/enterprise-profiles/ man-and-man-enterprise (accessed 2020-03-28)

17. GACC, Delivering on SDG through cooking. Global Alliance for Clean Cooking (GACC), Washington D.C. (2020). https://sustainabledevelopment.un.org/content/docu ments/11416Global\%20Allianc.pdf (accessed on 2020-03-28)

18. J.C. Ahiekpor, Cookstove sector of Ghana. A baseline study and survey of stakeholders. Energy Commission and UNDP Ghana, (2014). https://www.undp.org/content/dam/ ghana/docs/Doc/Susdev/UNDP_GH_SUSDEV_SE4ALL Cookstove $\% 20$ Sector $\% 20$ of $\% \overline{2} 0$ Ghana.pdf ${ }^{-}$(accessed 2020-04-20)

19. M. Bryden, D. Still, P. Scott, G. Hoffa, D. Ogle, R. Bailis, K. Goyer, Design Principles for Wood Burning Cook Stoves, Aprovecho Research Center, Shell Foundation, and United States Environmental Protection Agency, USA (2005)

20. GACC, The Water Boiling Test Version 4.2.3. Cookstove Emissions and Efficiency in a Controlled Laboratory Setting. Global Alliance for Clean Cookstove (GACC), Washington, 
DC, USA (2014). Released 19 March 2014. https:// cleancookstoves.org/binary-data/DOCUMENT/file/000/000/ 399-1.pdf (accessed 2020-03-20)

21. GACC, Handbook for biomass cookstove research design and development. A practical guide for implementing recent advances (2014) https://www.safefuelandenergy.org/files/ 517-1.pdf (accessed 2020-03-23)

22. GACC, The water boiling test 4.2.3 cookstoves emissions and efficiency in a controlled laboratory setting (Global Alliance for Clean Cookstoves (GACC), Washington DC, 2014)

23. J. Jetter, Y. Zhao, K.R. Smith, B. Khan, P. Decarlo, M.D. Hays, U. States, Pollutant emissions and energy efficiency under controlled conditions for household biomass cookstoves and implications for metrics useful in setting international test standards, Environ. Sci. Technol. 46, 10827-10834 (2012)

24. G. Boafo-Mensah, K. Ampomah-Benefo, M.A. Bentumah Animpong, W.O. Oduro, E.N. Kotey, K. Akufo-Kumi, G.N. Laryea, Thermal efficiency of charcoal fired cookstoves in Ghana, Glob. Adv. Res. J. Eng. Technol. Innov. 2, 102-110 (2013)

25. G. Obeng, E. Mensah, G. Ashiagbor, O. Boahen, D. Sweeney, Watching the smoke rise up: Thermal efficiency, pollutant emissions and global warming impact of three biomass cookstoves in Ghana, Energies 10, 641 (2017)

26. N. MacCarty, D. Still, D. Ogle, Fuel use and emissions performance of fifty cooking stoves in the laboratory and related benchmarks of performance, Energy Sustain. Dev. 14, 161-171 (2010)

27. S.S. Saiyyadjilani, P.G. Tewari, R. Tapaskar, A.P. Madival, M. Gorawar, P.P. Revankar, Design of Improved Biomass Cook Stove for Domestic Utility, edited by P.M. Pawar et al., Springer International Publishing AG 2018, Techno-Societal (2016)

28. A. Hugh, The Kenya Ceramic Jiko: A Manual for Stove Makers, Intermediate Technology Publications, UK (1991)

29. UNBS, Energy efficiency stoves: household biomass stoves, performance requirements and test methods. Uganda National Bureau of Standards (UNBS), US 761 (2007)

30. Lakeside Pottery, Clay the drying and firing process. Delaware, USA (2020). http://www.lakesidepottery.com/ HTML\%20Text/Tips/Clay\%20drying\%20and\%20firing\% 20process.htm (accessed 2020-03-39)
31. M. Hamburg, Basic Statistics: A Modern Approach, Harcourt Brace Jovanovich Publishers, Third Edition, Orlando, Florida, USA (1985)

32. M. Kelly, R.A. Donnelly, The Humongous Book of Statistics Problems, Penguin Group, USA (2009)

33. H.S. Drier, The Normal Distribution, Adapted from W.F. Coleman (1997). www.teacherlink.org/content/math/inter active/excelfiles/normaldist.xls, 2000 (accessed 2020-04-09)

34. Energypedia, Charcoal cookstoves. GIZ HERA cooking compendium. A practical guidebook for implementers of cooking energy interventions (2018) https://energypedia. info/wiki/Charcoal_Cookstoves (accessed on 2020-04-21)

35. Intermediate Technology, Stove and household energy. Boiling point; No 31, Issue 01-36, August (1998). Intermediate Technology Development Group (ITDG) and GTZ.

36. A.K. Plappally, I. Yakub, L.C. Brown, W.O. Soboyejo, A.B. O. Soboyejo, Physical properties of porous clay ceramic-ware, J. Eng. Mater. Technol. 133, 031004-1 (2011)

37. C. Pesambili, F. Magessa, N. Mwakabuta, Sazawa Charcoal stove designed for efficient use of charcoal, in Int. Conf. on Industrial Design Engineering 2003 (USDM, Dar es Salam, 2003), pp. $17-18$

38. H. Allan, Kenya Ceramic Jiko: A manual for stove makers, Intermediate Technology Publications, UK (1999)

39. L. Clough, The improved cookstove sector in East Africa: experience from the Developing Energy Enterprise Programme (DEEP) (GVEP-Global Village Energy Partnership International, London, UK, 2012), Vol. 108

40. M. Mahajan, Statistical quality control, Dhanpat Rai \& Co. (P) Ltd. Educational \& Technical Publishers, New Delhi, India (1999)

41. M.P. Kshirsagar, V.R. Kalamkar, A comprehensive review on biomass cookstoves and a systematic approach for modern cookstove design, Renew Sustain Energy Rev 30, 580-603 (2014)

42. J. Boyles, R.F. Orge, Performance of the continuous-type rice hull carbonizer as heat source in food product processing, OIDA Int. J. Sustain. Dev. 8, 25-34 (2015)

43. E. Adkins, E. Tyler, J. Wang, D. Siriri, V. Modi, Field testing and survey evaluation of household biomass cookstoves in rural sub-Saharan Africa, Energy Sustain Dev 14, 172-185 (2010)

Cite this article as: Kenneth Donkor, George Yaw Obeng, Richard Opoku, Anthony Agyei-Agyemang, Production processes and statistical analysis of ceramic liner-hole parameters for sustainability and improved thermal efficiency of clean biomass stoves, Renew. Energy Environ. Sustain. 6, 23 (2021) 